\title{
pi-conjugation and charge polarization in fluorene-dibenzothiophene-S,S- dioxide co-oligomers by Raman spectroscopy and quantum chemistry
} Zafra, Jose L.; Casado, Juan; Perepichka, Iryna I.; Perepichka, Igor F.; Bryce, Martin R.; Ramirez, Francisco J.; Lopez Navarrete, Juan T.

\section{Journal of Chemical Physics}

DOI:

$10.1063 / 1.3526487$

Published: 28/01/2011

Publisher's PDF, also known as Version of record

Cyswllt i'r cyhoeddiad / Link to publication

Dyfyniad o'r fersiwn a gyhoeddwyd / Citation for published version (APA):

Zafra, J. L., Casado, J., Perepichka, I. I., Perepichka, I. F., Bryce, M. R., Ramirez, F. J., \& Lopez Navarrete, J. T. (2011). pi-conjugation and charge polarization in fluorene-dibenzothiopheneS,S-dioxide co-oligomers by Raman spectroscopy and quantum chemistry. Journal of Chemical Physics, 134(4), [044520]. https://doi.org/10.1063/1.3526487

\footnotetext{
Hawliau Cyffredinol / General rights

Copyright and moral rights for the publications made accessible in the public portal are retained by the authors and/or other copyright owners and it is a condition of accessing publications that users recognise and abide by the legal requirements associated with these rights. study or research.

- Users may download and print one copy of any publication from the public portal for the purpose of private

- You may not further distribute the material or use it for any profit-making activity or commercial gain

- You may freely distribute the URL identifying the publication in the public portal ?
}

Take down policy

If you believe that this document breaches copyright please contact us providing details, and we will remove access to the work immediately and investigate your claim. 


\title{
$\pi$-conjugation and charge polarization in fluorene- dibenzothiophene-S,S-dioxide co-oligomers by Raman spectroscopy and quantum chemistry
}

\author{
José L. Zafra, ${ }^{1}$ Juan Casado, ${ }^{1}$ Iryna I. Perepichka, ${ }^{2}$ Igor F. Perepichka, ${ }^{3}$ Martin R. Bryce, ${ }^{4}$ \\ Francisco J. Ramírez, ${ }^{1}$ and Juan T. López Navarrete ${ }^{1, a)}$ \\ ${ }^{1}$ Departamento de Química Física, Universidad de Málaga, Málaga 29071, Spain \\ ${ }^{2}$ Département de Chimie, Université de Montréal, Montréal, Quebec H3C 3J7, Canada \\ ${ }^{3}$ Department of Chemistry, Bangor University, Bangor, Gwynedd LL57 2UW, United Kingdom \\ ${ }^{4}$ Department of Chemistry, Durham University, Durham DH1 3LE, United Kingdom
}

(Received 16 June 2010; accepted 19 November 2010; published online 27 January 2011)

\begin{abstract}
The Raman spectra of a series of fluorine (F)/dibenzothiophene-S,S-dioxide co-oligomers (S) of different length and alternation sequences in their backbones (FSF, FFSFF, FSFSF, and FASAF; A is the $-\mathrm{C} \equiv \mathrm{C}-$ bridge) have been recorded and simulated theoretically. It is shown that Raman spectroscopy is useful to probe $\pi$ conjugation and ground state electron polarization in these molecules, phenomena directly related with the existence of intramolecular charge-transfer processes owing to the combination of electron donor (fluorene) and acceptor (dibenzothiophene-S,S-dioxide) groups. Their geometric, electronic, and vibrational properties have been studied by density functional theory B3LYP/6-311G(2d,p) quantum chemical calculations and compared with those for fluorene homooligomers. Comparative studies in solution/solid/melted phase led to the conclusion that the Raman wavenumbers are also sensitive to intermolecular interactions. (C) 2011 American Institute of Physics. [doi:10.1063/1.3526487]
\end{abstract}

\section{INTRODUCTION}

Since the discovery of electroluminescence in poly- $p$ phenylenevinylene by the Cambridge group, ${ }^{1}$ considerable efforts have been made to develop various classes of conjugated polymers and copolymers as active layers of light-emitting devices (LEDs) for display technologies ${ }^{2-4}$ and, more recently, for solid state lighting applications. ${ }^{5}$ This technology offers simpler processability of materials from solution, low cost production (compared to vacuum deposition technique), low energy consumption, and easy tunability of spectral emissions through the wide range of chemical modifications of the polymer structure. Semiconductive conjugated polymers (and low molecular weight monodisperse conjugated oligomers) are emerging materials for a wide range of applications in molecular and plastic electronics: organic field-effect transistors (OFET), organic photovoltaic cells (OPV), logic circuits, nonlinear optics, sensors, and biosensors, etc. ${ }^{6}$

Structurally well-defined and monodisperse oligomers, which are intermediate between small molecules and high molecular weight polymers, not only play an important role as model compounds for deep insight into electronic processes in conjugated polymers and understanding structure-property relationships, but also occupy their own niche as materials for organic electronics $^{7-9}$ (and in the current hot area of single molecule electronics ${ }^{10,11}$ ).

Among many classes of $\pi$-conjugated polymers (polypheny-lenes, poly-p-phenylenevinylenes, poly- $p$ -

\footnotetext{
a) Author to whom correspondence should be addressed. Electronic mail: teodomiro@uma.es.
}

phenyleneethynylenes, polythiophenes, and polycarbazoles), polyfluorenes have been recognized as unique high bandgap polymers for organic electronics and optoelectronics applications, particularly for organic LEDs. ${ }^{12,13}$ For the past decade or so of intense studies, polyfluorene homopolymers and copolymers have emerged as leading electroluminescent materials, which possess bright blue emission, high hole, and electron mobility, relatively high (for high bandgap polymers) electro- and photo- and environmental stability. ${ }^{2,3}$ Structural variations in fluorene-based copolymers allow tuning of the emission from the deep blue to the near-infrared region and modulation of many other features of these materials (valence and conducting bands levels, charge mobility, and morphology). Fluorene building blocks have also been implemented in various copolymers for applications in OFETs, OPVs, sensors, etc.

The concept of alternation of conjugated building blocks with different highest occupied molecular orbital/lowest unoccupied molecular orbital (HOMO/LUMO) energies is widely used for tuning the band gap of conjugated donor$\pi$-acceptor copolymers and co-oligomers thereby modulating the spectral absorption/emission, electrochemical redox potentials, and charge mobilities in these materials. ${ }^{14}$ Pushpull donor- $\pi$-acceptor conjugates possess nonlinear optical properties, particularly high cross-section of two-photon absorptions (TPA), and various materials have been developed and studied for two- and three-photon absorptions, TPA fluorescence, optical limiting, and other nonlinear optics applications. ${ }^{15}$ Small energy gap donor- $\sigma$-acceptor molecules have been widely studied as unimolecular rectifiers of electrical current. ${ }^{16,17}$ 


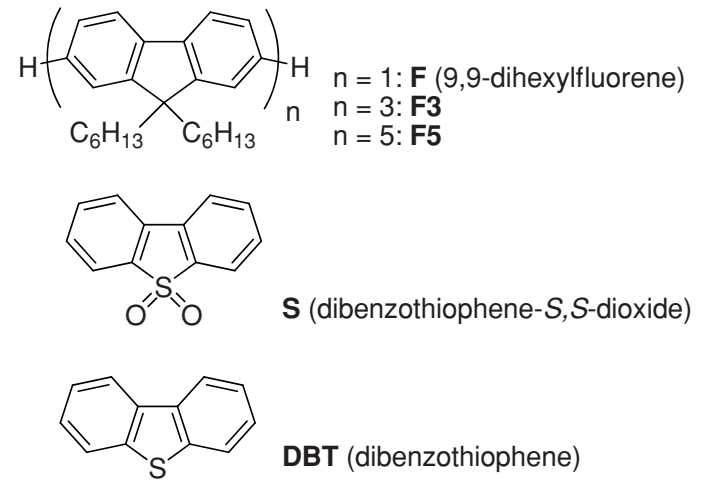

FIG. 1. Chemical structures of F, S, and DBT moieties.

The structure of the fluorene molecule $(\mathrm{F})$ consists of two benzene rings coplanarized by a bridging $s p^{3}$ carbon atom (Fig. 1). This coplanarity gives polyfluorene greater conjugation length compared to "unbridged" polyphenylenes. Dibenzothiophene (DBT) and dibenzothiophene-S,S-dioxide (S) moieties, in which the $s p^{3}$ carbon atom is substituted by a sulphur atom and a sulphonyl group, respectively, are topologically similar to fluorene (Fig. 1). Dibenzothiophene$S, S$-dioxide is an electron deficient molecule due to electron-withdrawing effect of the $\mathrm{SO}_{2}$ group, in fact, we have recently applied the donor-acceptor concept in the design of $\mathrm{F} / \mathrm{S}$ oligomers combining electron-rich $\mathrm{F}$ and electron-deficient $\mathrm{S}$ units (FSF, FSFSF, FFSFF, and FASAF). ${ }^{18,19}$ (For review on co-oligomers and copolymers using electron-deficient thiophene-S,S-dioxide moieties, see Ref. 20). It was realized that such oligomers possess high photoluminescence efficiency in both solution and the solid state, reversible oxidation and reductions to radical ions in electrochemical experiments, and high stability toward degradation. Moreover, it was demonstrated, that while a subtle charge transfer is observed for their ground states (i.e., also referred in the following as ground state electronic polarization), and an efficient intramolecular charge transfer (ICT) was observed in the excited state after photon absorption. The simultaneous existence of highly emissive locally excited (LE) and ICT excited states resulted in dual fluorescence from both excited states, broadening the emission spectra of the co-oligomers. ${ }^{19}$ This phenomenon of dual fluorescence was exploited in random $\mathrm{F} / \mathrm{S}$ copolymers $\left[(\mathrm{F})_{x} /(\mathrm{S})_{y}\right]_{n}$, which also showed efficient dual emission in both photoluminescence ${ }^{21}$ and electroluminescence ${ }^{22}$ processes with an increased contribution of ICT emission when the amount of $\mathrm{S}$ units in the copolymer backbone was increased. Efficient single-layer polymer LEDs with broadened electroluminescence have been developed for random $\left[(\mathrm{F})_{x} /(\mathrm{S})_{y}\right]_{n}$ copolymers achieving an external efficiency of electroluminescence of $\sim 1.1-1.3 \%$ and brightness of $\sim 4600-5090 \mathrm{~cd} \mathrm{~m}^{-2}$ at a higher loading of $\mathrm{S}$ units $(y \sim 0.15-0.30){ }^{22} \quad$ Electron-deficient dibenzothiophene- $S$, $S$-dioxide moieties have also been used for spectral stabilization of blue emission of fluorene copolymers (with varied loadings of S units in the backbone) (Ref. 23) and in design of polymers for phosphorescent LEDs. ${ }^{24}$ Recently, efficient blue-emitting LEDs based on molecular materials containing
S units have also been demonstrated. ${ }^{25}$ In summary, there is a critical influence of the donor-to-acceptor interaction in the properties of the excited states of these molecules which originates exploitable optical properties in technological devices. This donor-to-acceptor interaction is reflected in the ground state as well as a polarization of the $\pi$-electron cloud toward the acceptors which is the structural property that anticipated the relevant intramolecular charge transfer. In the absence of charge polarization or coexisting with it, the phenomenon of $\pi$ conjugation between the donor and acceptor units always takes place.

Among the chemical systems for which vibrational spectroscopy can provide useful structural information, polyconjugated materials is one of the best examples. ${ }^{26}$ Vibrational spectra are sensitive to a wide variety of structural changes in these materials. In particular, Raman spectroscopy probes the coupling between electronic states and vibrational modes, which greatly influence the nature of the excited states involved in luminescence phenomena. This technique has been shown to be particularly useful in estimating the degree of $\pi$ conjugation in neutral oligomers ${ }^{27-29}$ and analyzing the efficiency of the intramolecular charge transfer (ground state polarization of the electronic cloud due to the donor-acceptor interaction) in $\pi$-conjugated NLOphores (nonlinear optical chromophores). ${ }^{30,31}$ The usual observation of rather a few and overwhelmingly strong Raman scatterings, even for molecular materials with complex chemical structures, has been successfully explained in the framework of the Effective Conjugation Coordinate (ECC) theory: the ECC mode excites the electron-phonon coupling mechanism governing many physical properties of the conjugated system, for example, the binding energy of excitons, etc. ${ }^{32}$

As a probe of the electronic structure of these materials and owing to the interest in a better knowledge of the molecular impact of intrinsically different phenomena such as $\pi$ conjugation (due to the lateral overlapping among carbon $p_{z}$ orbitals) and ground state charge polarization (due to donor-acceptor nature of the interacting units), in the present work we have used Raman spectroscopy to characterize the interchromophore coupling between $\mathrm{F}$ and $\mathrm{S}$ building blocks in the co-oligomers cited above ${ }^{18,21}$ in order to establish new structure-property relationships. We have selected the oligomers FSF, FSFSF, FFSFF, and FASAF (Fig. 2) as model compounds to probe the impact in the electronic structure of structural variables such as chain length and donoracceptor interaction. The experimental Raman spectra are interpreted with the help of density functional theory (DFT) quantum chemistry calculations. In order to investigate the effect of the S moiety in the structural properties of these cooligomers, calculations were also performed for a series of related molecules in which this moiety is removed (Fig. 3).

\section{METHODS}

\section{A. Raman measurements}

Raman spectra at room temperature were recorded using a Bruker Senterra dispersive spectrometer provided with 

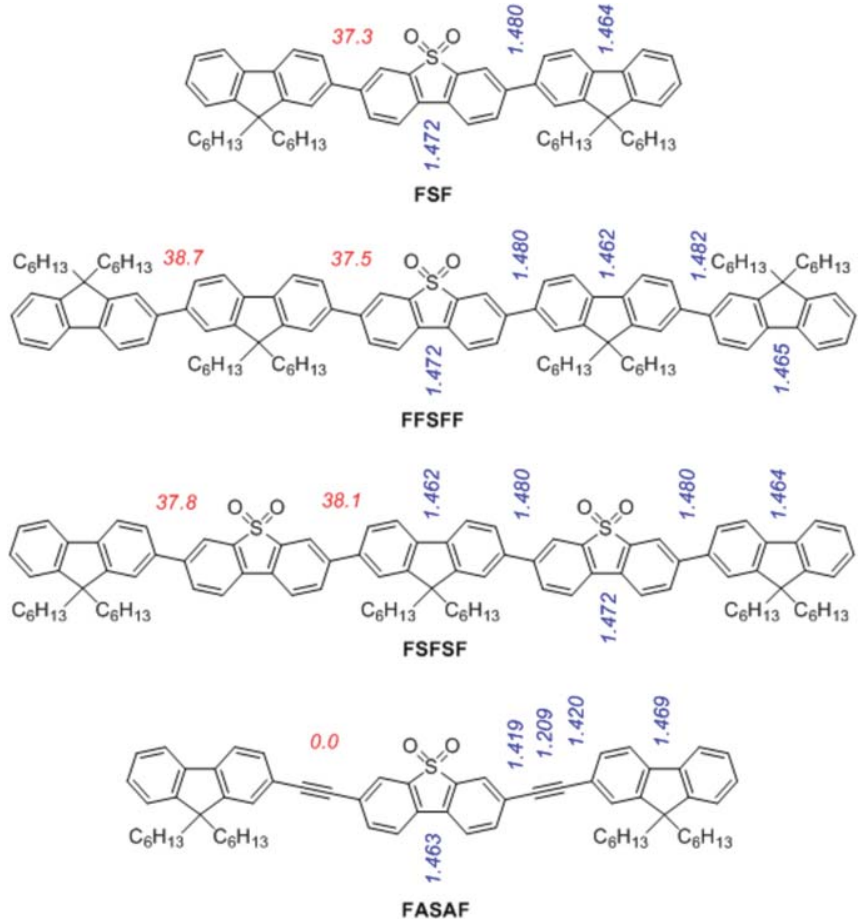

FIG. 2. Chemical structures of co-oligomers studied in this work. DFT B3LYP/6-311G(2d,p) calculated interbenzene bond distances and dihedral angles between the moieties have been shown 9,9-dimethylfluorene substituted analogs.

an Olympus BX optical microscope. Typical experimental settings for the solid samples measurements were the following: excitation radiation at $532 \mathrm{~nm}$ (as generated by an $\mathrm{Ar}^{+}$ laser with $200 \mathrm{~mW}$ laser power), backscattering collection of the scattered radiation, spectral resolution better than $3 \mathrm{~cm}^{-1}$, and spatial resolution of $1 \mu \mathrm{m}$ with 500 scans accumulated for each sample. Spectra of the samples dissolved in dichloromethane (DCM) were obtained using a Bruker VERTEX 70 FT system provided by a FRA106/S module for Raman measurements. Melted samples were studied using a variable-temperature cell Specac P/N 21525 coupled to the Raman module. This accessory was equipped with a copper constantan thermocouple, which allowed us to vary the temperature from -170 to $+250{ }^{\circ} \mathrm{C}$. In these experiments, the samples were studied with the solid dispersed in a $\mathrm{KBr}$ pellet and the excitation wavelength was $1064 \mathrm{~nm}$ as generated by a $\mathrm{Nd}-\mathrm{YAG}$ laser working at $500 \mathrm{~mW}$. In all the cases individual scans were examined by the recording routine before averaging, being automatically discarded when the mean intensity deviations were greater than $10 \%$ over the full interferogram length. Measurement and treatment of the vibrational spectra were carried out using the OPUS 6.5 (c) spectroscopic software.

\section{B. Calculation method}

The GAUSSIAN03 package of programs ${ }^{33}$ was used for DFT quantum chemical calculations. The Becke's three parameter (B3) (Ref. 34) gradient-corrected exchange functional was used with Lee-Yang-Parr (LYP) nonlocal correlation functional. ${ }^{35,36}$ Ground state electronic properties and
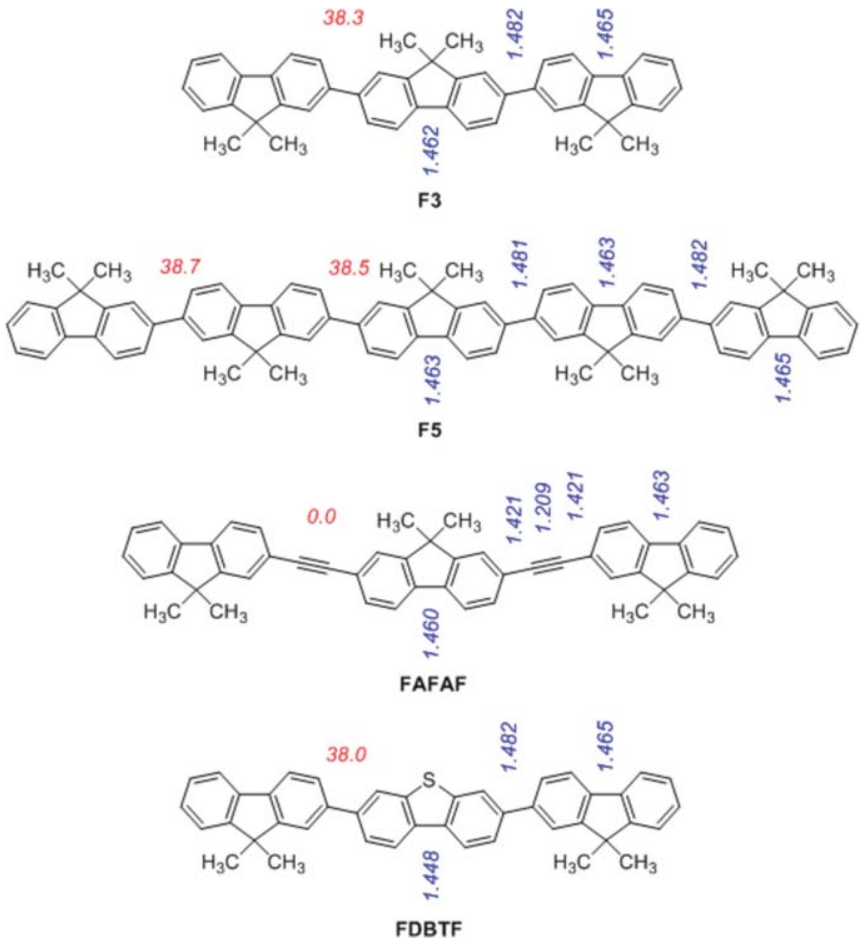

FIG. 3. DFT B3LYP/6-311G(2d,p) calculated interbenzene ring bond distances and dihedral angles between the moieties in FFF, FFFFF, FAFAF, and FBDTF oligomers.

vibrational features were obtained using the split-valence 6-311G(2d,p) basis set ${ }^{37,38}$ (for comparison with previous data on frontier orbital energies, ${ }^{18}$ some oligomers have also been optimized using 6-31G(d) basis set). The minimum energy structure (B3LYP/6-311G(2d,p)) was achieved by allowing all the geometrical parameters to vary independently. Harmonic force constants, in Cartesian coordinates, were evaluated at the ground state optimized geometry using analytical second derivatives. Raman intensities were calculated by numerical differentiation of dipole derivatives with respect to the electric field. ${ }^{39}$ The theoretical spectra were obtained from the DFT intensities in combination with the calculated vibrational wavenumbers uniformly scaled by factor of $0.98{ }^{40}$ Every band was represented by a Gaussian function of $20 \mathrm{~cm}^{-1}$ full width at half maximum (FWHM). To diminish the computation time, in calculations of fluorene and its oligomers (FSF, FSFSF, FFSFF, FASAF, FDBTF, FAFAF, $\mathrm{F} 3$, and F5), two hexyl $\left(-\mathrm{C}_{6} \mathrm{H}_{13}\right)$ substituents at nine position of the fluorene rings have been replaced with shorter methyl $\left(-\mathrm{CH}_{3}\right)$ groups. Such replacement has negligible effect on the energies of frontier orbitals of oligomers, which are located on the $\pi$ system of the backbone, while side chains are connected to the benzene rings of the fluorene moiety through nonconjugated $s p^{3}$ hybridized carbon (C-9 of the fluorene). ${ }^{41,42}$

\section{RESULTS AND DISCUSSION}

\section{A. A detailed analysis of the Raman spectrum of FSF as the reference molecule}

Figure 4 shows the solid state experimental and B3LYP/6-311G(2d,p) theoretical Raman spectra of FSF 


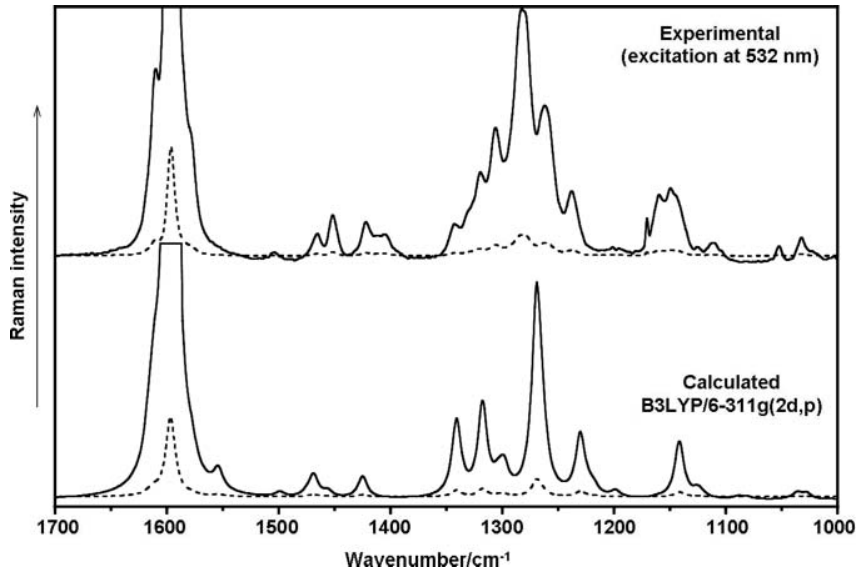

FIG. 4. Experimental solid-state and B3LYP/6-311G(2d,p) Raman spectra of FSF.

between 1700 and $1000 \mathrm{~cm}^{-1}$, which is the region containing the vibrations directly coupled with the electronic structure (i.e., containing valuable structure-spectroscopic relationships). We have included as supplementary material ${ }^{43}$ a full list of the theoretical and experimental wavenumbers and intensities for FSF in this region together with their predicted assignments.

The main feature to be emphasized is the low number of visible Raman bands compared with the number of molecular vibrations (i.e., $3 \mathrm{~N}-6$, with $N$ being the number of atoms). The spectra are dominated by a strong peak around $1600 \mathrm{~cm}^{-1}$, which is accompanied by a set of weak overlapped bands centered around $1300 \mathrm{~cm}^{-1}$. According to the ECC theory for one-dimensional $\pi$-conjugated chains, ${ }^{32}$ the Raman bands associated to the structural evolution from a benzenoid structure to a quinoid one (usually denoted as the $Я$ or ECC vibrational coordinate) are selectively enhanced. This is founded in the benzenoidlike character of the ground electronic state and the quinoidal-like character of the excited state pumped during Raman excitation (see the HOMO and LUMO wavefunctions in next sections to derive the benzenoid and quinoidal features). This $Я$ vibration always belongs to the totally symmetric species, being usually represented by a linear combination of alternating skeletal $\mathrm{C}-\mathrm{C}$ and $\mathrm{C}=\mathrm{C}$ stretching modes. The $Я$ vibration excites the electron-phonon mechanism and, as a consequence, their associated Raman bands become sensitive to the electronic property.

Going in more detail into Fig. 4, the correlations between the measured and the predicted wavenumbers were based on the Raman intensities whereas the theoretical description of the motions were deduced from the calculated eigenvectors (in Fig. 5). Table I summarizes these experimental-totheoretical correlations in FSF for the most significant vibrations. The most intense band was measured at $1596 \mathrm{~cm}^{-1}$ and predicted at $1597 \mathrm{~cm}^{-1}$. The associated eigenvector indicates that this vibration is largely localized at the central $\mathrm{S}$ moiety and describes an aromatic-to-quinoid motion of the skeletal CC bonds. The atomic displacements within the benzene rings are well fitted to the 8a vibration of the well-known Wilson's notation in benzene ${ }^{44}$ thus supporting the predominance of the aromatic versus the quinoid structure for FSF.
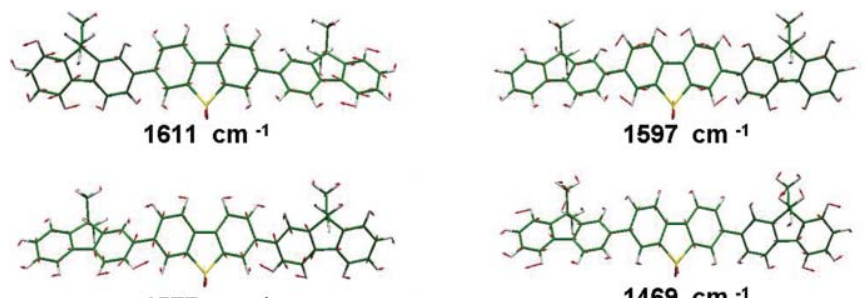

$1469 \mathrm{~cm}^{-1}$

$1577 \mathrm{~cm}^{-1}$

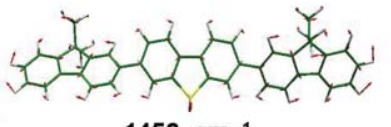

$1456 \mathrm{~cm}^{-1}$

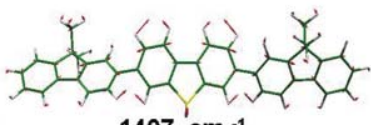

$1407 \mathrm{~cm}^{-1}$

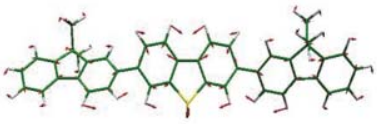

$1318 \mathrm{~cm}^{-1}$

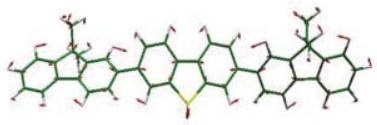

$1269 \mathrm{~cm}^{-1}$

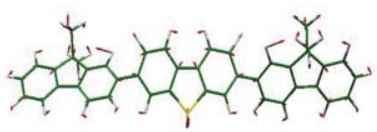

$1230 \mathrm{~cm}^{-1}$

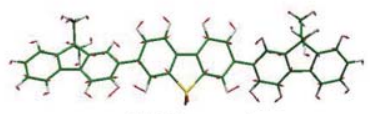

$1425 \mathrm{~cm}^{-1}$

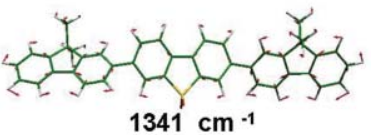

$1341 \mathrm{~cm}^{-1}$

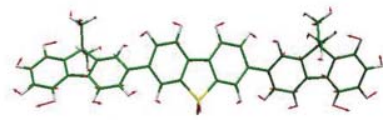

$1299 \mathrm{~cm}^{-1}$

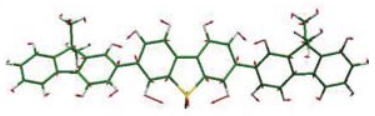

$1262 \mathrm{~cm}^{-1}$

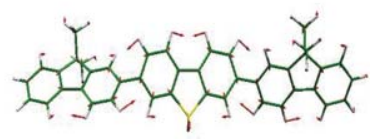

$1142 \mathrm{~cm}^{-1}$

FIG. 5. Calculated eigenvectors for FSF.

This intense peak is accompanied by two shoulders, at 1610 and $1576 \mathrm{~cm}^{-1}$, which were correlated with the calculated values at 1611 and $1577 \mathrm{~cm}^{-1}$. In the light of their respective eigenvectors, they are assigned to $\mathrm{C}=\mathrm{C}$ vibrations largely localized at the two outer fluorene moieties, with some contribution from the central dibenzothiophene group for the low frequency shoulder. None of them describe an aromatic-toquinoid transition, which agrees with the small intensities of their Raman features.

Between 1500 and $1400 \mathrm{~cm}^{-1}$ we can observe some overlapped bands whose eigenvectors mostly correspond to $\mathrm{C}-\mathrm{H}$ aromatic in plane bending vibrations with different locations in the molecule. The more intense Raman features were measured at $1466,1451,1425$, and $1405 \mathrm{~cm}^{-1}$, related to the calculated wavenumbers at $1469,1456,1425$, and $1407 \mathrm{~cm}^{-1}$, respectively. The vibrations at 1469 and $1456 \mathrm{~cm}^{-1}$ are fully localized on the $\mathrm{F}$ moieties and involve a slight contribution from the methyl bending modes. On the contrary, the band measured at $1405 \mathrm{~cm}^{-1}$ is assigned to $\mathrm{C}-\mathrm{H}$ bending vibrations of the $\mathrm{S}$ group. Both the $\mathrm{F}$ and the $\mathrm{S}$ moieties contribute to the eigenvector at $1425 \mathrm{~cm}^{-1}$.

The Raman spectrum of FSF shows a second group of bands between 1350 and $1200 \mathrm{~cm}^{-1}$ that can be assigned to mixture of $\mathrm{C}-\mathrm{C}$ stretches and $\mathrm{C}-\mathrm{H}$ bending modes. Here, the most intense feature is a doublet with a maximum at $1283 \mathrm{~cm}^{-1}$ correlated with the theoretical band at $1269 \mathrm{~cm}^{-1}$ that describes a normal mode spreading the whole molecule. Some less intense bands are detected at both sides of this 
TABLE I. Comparison between experimental and calculated Raman wavenumbers ${ }^{\mathrm{a}}$ and intensities ${ }^{\mathrm{b}}$, together with the proposed assignment ${ }^{\mathrm{c}}$.

\begin{tabular}{|c|c|c|c|c|c|c|c|c|c|c|c|c|c|c|c|c|}
\hline \multicolumn{4}{|c|}{ FSF } & \multicolumn{4}{|c|}{ FSFSF } & \multicolumn{4}{|c|}{ FFSFF } & \multicolumn{4}{|c|}{ FASAF } & \multirow{3}{*}{ Assignments } \\
\hline \multicolumn{2}{|c|}{ Calc. } & \multicolumn{2}{|c|}{ Exp. } & \multicolumn{2}{|c|}{ Calc. } & \multicolumn{2}{|c|}{ Exp. } & \multicolumn{2}{|c|}{ Calc. } & \multicolumn{2}{|c|}{ Exp. } & \multicolumn{2}{|c|}{ Calc. } & \multicolumn{2}{|c|}{ Exp. } & \\
\hline$\overline{\text { wn }}$ & $I$ & wn & $I$ & wn & $I$ & wn & $I$ & wn & $I$ & wn & $I$ & wn & $I$ & wn & $I$ & \\
\hline- & - & - & - & - & - & - & - & - & - & - & - & 2233 & 266 & 2201 & $\mathrm{~m}$ & $\nu(\mathrm{C} \equiv \mathrm{N})$ \\
\hline 1611 & 3 & 1610 & w & 1611 & 4 & 1609 & $\mathrm{sh}$ & 1607 & 43 & 1608 & $\mathrm{~m}$ & 1608 & 17 & 1607 & $\mathrm{sh}$ & $v(\mathrm{C}=\mathrm{C}) \mathrm{F}, \mathrm{S}$ \\
\hline 1597 & 49 & 1596 & $\mathrm{~s}$ & 1598 & 173 & 1597 & vs & 1598 & 148 & 1598 & vs & 1591 & 178 & 1592 & vs & $v(\mathrm{C}=\mathrm{C}) \mathbf{S}(\mathrm{ECC}$ mode $)$ \\
\hline 1577 & 1 & 1576 & sh & 1576 & 1 & 1575 & sh & 1576 & 2 & 1578 & $\mathrm{sh}$ & 1565 & 15 & 1569 & $\mathrm{w}$ & $v(\mathrm{C}=\mathrm{C}) \mathrm{F}, \mathrm{S}$ \\
\hline 1456 & 1 & 1451 & $\mathrm{w}$ & 1452 & 1 & 1448 & w & 1450 & 1 & 1449 & $\mathrm{w}$ & 1482 & 2 & 1483 & $\mathrm{w}$ & $v(\mathrm{C}=\mathrm{C}) \mathrm{F}, \delta(\mathrm{C}-\mathrm{H}) \mathrm{F}$ \\
\hline 1400 & 1 & 1405 & $\mathrm{vw}$ & 1407 & 2 & 1405 & $\mathrm{w}$ & 1408 & 2 & 1407 & $\mathrm{w}$ & 1413 & 2 & 1407 & w & $\delta(\mathrm{C}-\mathrm{H}) \mathrm{F}, v(\mathrm{C}=\mathrm{C}) \mathrm{F}$ \\
\hline 1318 & 5 & 1320 & w & 1350 & 11 & 1339 & $\mathrm{w}$ & 1350 & 11 & 1344 & w & 1312 & 18 & 1321 & $\mathrm{~m}$ & $v(\mathrm{C}=\mathrm{C}) \mathrm{S}, \delta(\mathrm{C}-\mathrm{H}) \mathrm{F}$ \\
\hline 1269 & 10 & 1282 & $\mathrm{~m}$ & 1284 & 29 & 1283 & $\mathrm{w}$ & 1290 & 27 & 1288 & $\mathrm{w}$ & 1298 & 6 & 1292 & w & $\delta(\mathrm{C}=\mathrm{C}) \mathrm{S}, \mathrm{F}, \delta\left(\mathrm{CH}_{3}\right) \mathrm{F}$ \\
\hline 1230 & 3 & 1238 & w & 1262 & 14 & 1263 & w & 1261 & 9 & 1263 & w & 1274 & 3 & 1272 & w & $v(\mathrm{C}=\mathrm{C}) \mathrm{S}, \delta\left(\mathrm{CH}_{3}\right) \mathrm{F}$ \\
\hline 1142 & 3 & 1149 & $\mathrm{w}$ & 1124 & 9 & 1139 & w & 1123 & 8 & 1135 & $\mathrm{w}$ & 1149 & 45 & 1137 & $\mathrm{~m}$ & $\delta(\mathrm{C}-\mathrm{H}) \mathrm{F}, \mathrm{S}$ \\
\hline
\end{tabular}

${ }^{\mathrm{a}}$ wavenumbers in $\mathrm{cm}^{-1}$

$\mathrm{b}_{\mathrm{s}}=$ strong; $\mathrm{m}=$ medium; $\mathrm{w}=$ weak; $\mathrm{v}=$ very $; \mathrm{sh}=$ shoulder

${ }^{\mathrm{c}} \nu=$ stretching; $\delta=$ bending.

doublet, namely at $1342,1319,1306,1262$, and $1238 \mathrm{~cm}^{-1}$ that are related with the calculated wavenumbers at 1341 , $1318,1299,1262$, and $1230 \mathrm{~cm}^{-1}$, respectively. With the exception of the band at $1262 \mathrm{~cm}^{-1}$, whose associated vibration is located at the S moiety, the rest of the bands are mainly placed on the outermost $\mathrm{F}$ groups. At lower wavenumbers, a multiplet of bands centred at $1149 \mathrm{~cm}^{-1}$ is observed, which should correspond with typical normal modes as that calculated for the band at $1142 \mathrm{~cm}^{-1}$.

It is interesting to relate the ECC mode frequency and the electronic structure with the torsion angle around the single CC bonds connecting the fluorenes and the dibenzothiophene dioxide, for example, in the simplest FSF case. We have calculated the HOMO-LUMO energy gap $\left(\Delta E_{\mathrm{H}-\mathrm{L}}\right)$ and the Raman spectra in several conformations. The results are summarized in Table II, while the theoretical Raman spectra are included as supplementary material. ${ }^{43}$ It is observed that the lowest $\Delta E_{\mathrm{H}-\mathrm{L}}$ and $\mathrm{ECC}$ frequencies are found for the fully planar structure which favors electron

TABLE II. DFT/B3LYP/6-311G(2d,p) HOMO-LUMO gap and ECC wavenumber as a function of the relative torsion around the two single CC bonds of FSF (considering methyl groups in the 1,9 positions of the fluorenes).

\begin{tabular}{lccc}
\hline \hline$\Phi_{1}{ }^{\mathrm{a}}$ & $\Phi_{2}{ }^{\mathrm{a}}$ & $\begin{array}{c}\Delta E_{\mathrm{H}-\mathrm{L}} \\
(\mathrm{eV})\end{array}$ & $\begin{array}{c}v_{1} \\
\left(\mathrm{~cm}^{-1}\right)\end{array}$ \\
\hline 0 & 0 & 3.395 & 1593 \\
0 & 45 & 3.557 & 1596 \\
0 & 90 & 3.704 & 1598 \\
45 & 45 & 3.746 & 1600 \\
45 & 90 & 3.944 & 1603 \\
90 & 90 & 4.186 & 1611 \\
$37^{\mathrm{a}}$ & $37^{\mathrm{a}}$ & 3.651 & 1597 \\
\hline \hline
\end{tabular}

$\overline{{ }^{a}} \Phi_{1}$ and $\Phi_{2}$ are the dihedral angles (in degrees) between the central S moiety and the two $\mathrm{F}$ groups of FSF as shown in the figure.

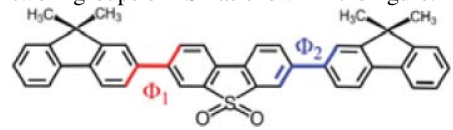

${ }^{b}$ Dihedral angles of the fully optimized structure. delocalization along the whole path from one fluorene to another. However, this conformation is not energetically stable owing to the steric repulsion between the hydrogen atoms of the benzene groups. On the contrary the conformer exhibiting a perpendicular disposition between the groups offers the worst condition for electronic communication among the three groups (highest $\Delta E_{\mathrm{H}-\mathrm{L}}$ and ECC frequency). The $\Delta E_{\mathrm{H}-\mathrm{L}}$ and ECC frequency on the geometry at the optimized energy indicate a good compromise as for the optimal conjugation along the whole molecular path.

\section{B. Experimental Raman spectra}

Figure 6 shows the solid state Raman spectra of the four co-oligomers, FSF, FSFSF, FFSFF and FASAF. Taking FSF as the reference molecule, the Raman spectra of the other longer oligomers (FSFSF, FFSFF, and FASAF) have been analyzed and highlight and exhibited the following features:

(i) In general, in the spectrum of FFSFF a slight reduction of the number of active bands (compared to FSF) was observed. The more intense peak $\left(1596 \mathrm{~cm}^{-1}\right)$ and the peak seen at $1283 \mathrm{~cm}^{-1}$ in FSF, are both up-shifted to 1598 and $1288 \mathrm{~cm}^{-1}$, respectively. The multiplet with a maximum at $1150 \mathrm{~cm}^{-1}$ was replaced by a single and more intense band at $1136 \mathrm{~cm}^{-1}$. The $I_{1598} / I_{1608}$ intensity ratio in FFSFF underwent a reduction regarding the $I_{1596} / I_{1610}$ ratio in FSF (see Fig. 7 for a zoom of these bands). As will be discussed later, intensity relationships in this region are useful to evaluate efficient conjugation and/or electronic polarization such as previously established for fluorene and in phenylene-based oligomers and polymers. ${ }^{45,46}$

(ii) In the Raman spectrum of FSFSF, a symmetrical oligomer with two $\mathrm{S}$ moieties and alternated $\mathrm{F} / \mathrm{S}$ mode, the shoulder at $1576 \mathrm{~cm}^{-1}$ disappeared. Similarly to FFSFF, a single band was observed at $1139 \mathrm{~cm}^{-1}$ (substituting the multiplet in FSF). On the contrary, two 


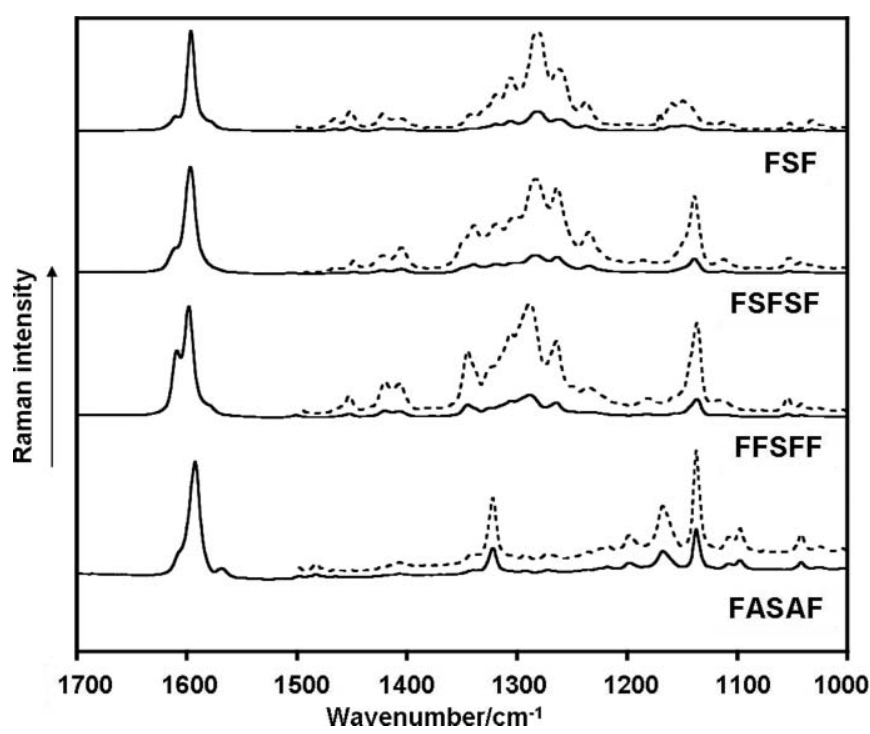

FIG. 6. Raman spectra of the F/S co-oligomers studied as solid samples.

bands at similar wavenumbers dominated the multiplet around at $1300 \mathrm{~cm}^{-1}$.

(iii) The Raman spectrum of FASAF, the oligomers in which $\mathrm{F}$ and $\mathrm{S}$ moieties are separated by a triple $-\mathrm{C} \equiv \mathrm{C}-$ bond bridge $(\mathrm{A})$, exhibited notable changes compared to FSF. First, a band appeared at $2201 \mathrm{~cm}^{-1}$, which was assigned to the stretching vibration of the $\mathrm{C} \equiv \mathrm{C}$ bonds. This value was appreciably lower compared with the usual $\mathrm{C} \equiv \mathrm{C}$ stretching wavenumber of $\mathrm{ca} .2270 \mathrm{~cm}^{-1}$ for nonconjugated systems ${ }^{47,48}$ providing evidence of bond weakening in FASAF by extension of conjugation along the main molecular axis. Moreover, the most intense band (1596 $\mathrm{cm}^{-1}$ in FSF) downshifted by 4-1591 $\mathrm{cm}^{-1}$ and its shoulder at higher wavenumbers disappeared. At lower wavenumbers, a new band at $1569 \mathrm{~cm}^{-1}$ emerged. The region between 1350 and $1050 \mathrm{~cm}^{-1}$ was also considerably different compared to that of FSF, dominated by two main peaks at 1321 and $1137 \mathrm{~cm}^{-1}$.

(iv) Figure 7(a) shows the spectral region between 1650 and $1550 \mathrm{~cm}^{-1}$ for FSF, FFSFF, and FSFSF normalized to the methylene bending vibration of the hexyl chains, $\delta\left(\mathrm{CH}_{2}\right)$, which appears near $1420 \mathrm{~cm}^{-1}$ for all of them (see the assignment of the $1450 \mathrm{~cm}^{-1}$ bands in the previous section). This vibrational mode is decoupled from the conjugational core and therefore the normalization relative to it can provide an evaluation of the Raman intensity evolution in the series. We focus our discussion in the region around $1600 \mathrm{~cm}^{-1}$. Increased $\pi$ conjugation in a homogeneous (same repeating unit) oligomeric series leads the ECC mode to largely contribute to a unique skeletal $v(\mathrm{C}=\mathrm{C} / \mathrm{C}-\mathrm{C})$ normal mode of the molecule. In consequence, the corresponding Raman band will be selectively enhanced and we will see an "apparent" simplification of the spectrum. In contrast, the spectral consequence of increasing donor-to-acceptor ICT or increasing ground

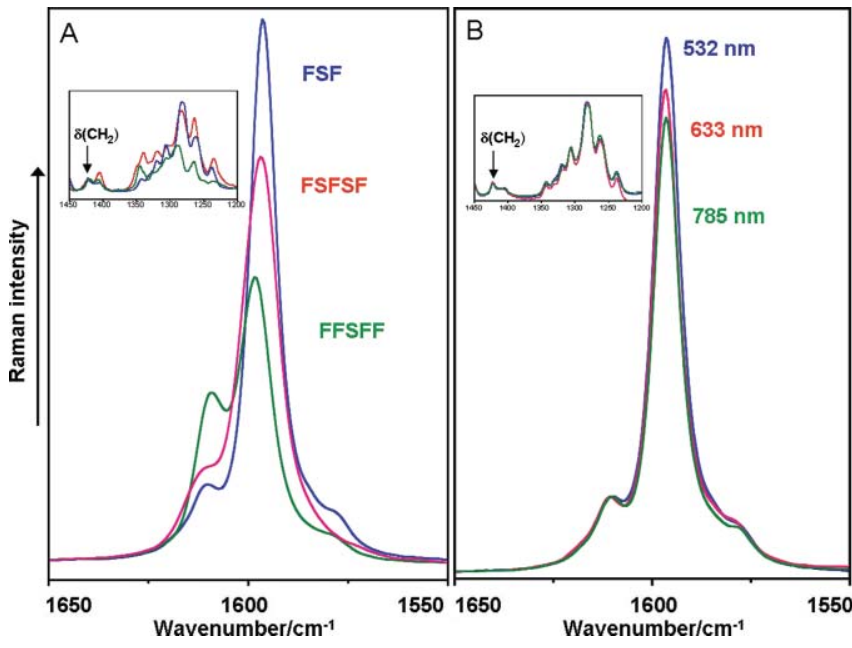

FIG. 7. Comparison between experimental Raman spectra in the ECC region. (A) Raman spectra of FSF, FSFSF and FFSFF. (B) Raman spectra of FSF taken with different laser excitation lines, namely 532, 633, and $785 \mathrm{~nm}$. All the spectra were normalized to the methylene bending band near $1420 \mathrm{~cm}^{-1}$.

state electron polarization is the appearance of bands both of the acceptor and of the donor. In summary, and as a guide, increment of $\pi$ conjugation simplifies the Raman spectrum while charge polarization induces either more bands on it or, alternately, equalizes the intensities of the donor and acceptor Raman bands. We find these features in the spectra of Fig. 7, where: (i) the spectrum of FFSFF shows an equalization of the $1610 / 1596 \mathrm{~cm}^{-1}$ bands which is in agreement with the most pronounced donor-to-acceptor interaction given the combination of the best donor (a bifluorene moiety) with S; (ii) in FSF the electron polarization extend decreases compared to FFSFF and the phenomenon of $\pi$ conjugation dominates, thus the Raman spectrum is the simplest; (iii) FSFSF shows a intermediate situation in accordance with showing a large path of conjugation (i.e., five units) but with a electron polarization weakened by the competition of two opposed donor-toacceptor sites acting over the central fluorene unit. This discussion is also in line with the energy gaps evolution which is reduced in the sense FSF $\rightarrow$ FSFSF $\rightarrow$ FFSFF such as it will be described in next sections.

(v) Figure 7(b) displays the FSF Raman spectra taken with several laser excitations as a representative example. The spectra are normalized regarding the same $\delta\left(\mathrm{CH}_{2}\right)$ mode selected in the preceeding section. It is observed that by approaching the laser excitation energy to the optical energy gap, an increase of the Raman activity is detected in line with the coupling between the $Я$ mode and the relevant electronic excitations.

\section{DFT calculations: Geometric and electronic structures}

To get insight of the influence of the chemical functionalities on the electronic properties of the oligomers we have performed geometry optimizations within the framework of 
FSF

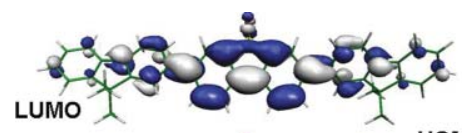

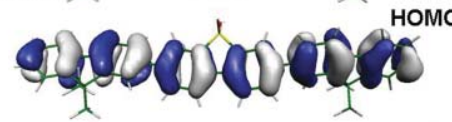
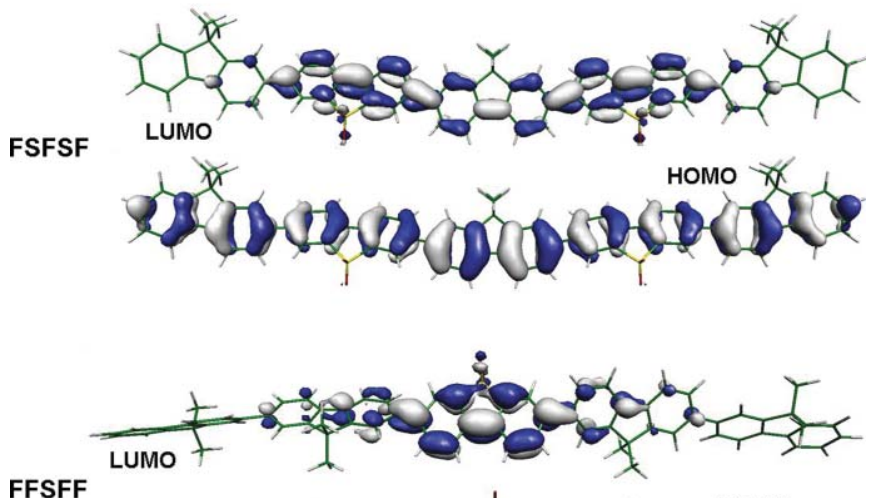

FFSFF
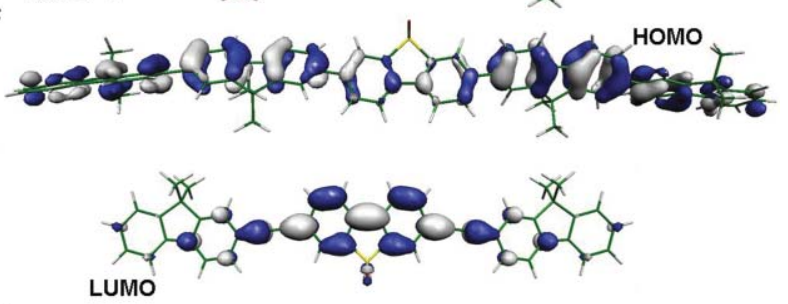

FASAF

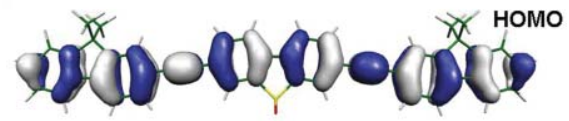

FIG. 8. B3LYP/6-311G(2d,p) optimized structures and frontier orbitals of the $\mathrm{F} / \mathrm{S}$ co-oligomers.

the DFT theory at B3LYP/6-311G(2d,p) level. Figure 8 shows the minimum energy structures of FSF, FSFSF, FFSFF, and FASAF. The first three of these co-oligomers are not planar with dihedral angles between the $\mathrm{F}$ and $\mathrm{S}$ moieties of $37.3^{\circ}-$ $38.1^{\circ}$ (38. $7^{\circ}$ for F-F dihedral angle in FFSFF) (Fig. 2), which are very close to the dihedral angles between $\mathrm{F}$ moieties in fluorene homo-oligomers (38.3-38. $7^{\circ}$ for F3 and F5, Fig. 3). We have to take into account that the structures of $F$ and $S$ are quite similar, as demonstrated by X-ray analysis. ${ }^{49}$ Such a deviation from planarity is caused by steric hindrance between the hydrogens of adjacent moieties and surely interferes with the extension of the $\pi$ conjugation and/or charge polarization along the principal molecular axis. Planarity has been observed in a $\mathrm{S}$ core substituted with pyridine, due to $\mathrm{N}^{-} \mathrm{H}$ interactions. ${ }^{24}$

In $\mathrm{F} / \mathrm{S}$ co-oligomers, the $\mathrm{C}-\mathrm{C}$ interbenzene distances of $1.462-1.465 \AA$ in the $\mathrm{F}$ moieties show very small variations which depend on the position of the F fragments and, on the other hand, are similar to those for F3 and F5 homo-oligomers (Figs. 2 and 3). In the $\mathrm{S}$ unit this distance is somewhat larger (1.472 $\AA$ ) due to the bigger size of the sulfonyl group. In this sense, the F-S and F-F inter-ring $\mathrm{C}-\mathrm{C}$ distances are somewhat larger (1.480-1.482 ̊). Assuming that these $\mathrm{C}-\mathrm{C}$ bonds bear the relevant inter-ring electronic effect, these values, being intermediate between the single $\mathrm{C}-\mathrm{C}$ and double $\mathrm{C}=\mathrm{C}$ bonds, reflect the degree of interaction between adjacent aromatic benzene rings, not only inside the fused groups but also between them. These structural properties will be useful to understand the Raman frequency behavior in the series. This fact is also supported by the topology of the highest occupied molecular orbital in which the electronic density spreads over the whole molecule (Fig. 8). Yet, there are some differences in localization of the HOMOs for the co-oligomers.

It is well established that for $\pi$-conjugated homooligomers the largest HOMO coefficients are at the central unit, with a decrease of the HOMO population toward the molecular ends. For the co-oligomers formed by units of different electronic nature, it turns out that their HOMO and lowest unoccupied molecular orbital display significant different energies and wavefunctions which depends of the sequence of the moieties in the backbone. This explains the predominant localization of the HOMO at the ends of FFSFF, namely on the bifluorene donor fragments, and on the central fluorene moiety in the case of FSFSF (Fig. 8).

In contrast, in the sterically unhindered acetylenebridged FASAF oligomer the three aromatic moieties (the two $\mathrm{F}$ and $\mathrm{S}$ ) lie in the same plane. This planarity facilitates conjugation along the backbone and consequently the interring $\mathrm{C}-\mathrm{C}$ distance in the central $\mathrm{S}$ moiety becomes shorter $(1.463 \AA)$. Also, the formally single $\mathrm{C}-\mathrm{C}$ connecting the two $\mathrm{C} \equiv \mathrm{C}$ is rather short (1.419-1.420 $\AA$ ) (Fig. 2; see also distances for FAFAF in Fig. 3). On the other hand, the distribution of the HOMO coefficients in FASAF is similar to that in FSF with the $\mathrm{C} \equiv \mathrm{C}$ moiety being predominantly involved in the HOMO (Fig. 8). Overall, these structural features denote an apparent pseudoaromatic to pseudoquinoid transition in going in the series from FSF to FASAF.

A summary of the energy of the frontier orbital, the calculated HOMO-LUMO energy gaps $\left(E_{\mathrm{g}}\right)$ and the experimental absorption wavelengths (measured at the largest wavelength) for $\mathrm{F}$ and $\mathrm{S}$ monomers, as well as for homo-oligomers (F3, F5) and co-oligomers (FAFAF and FSF, FASAF, FFSFF, FSFSF) has been included as supplementary material. $S$ has substantially lower HOMO and LUMO energies compared to F (by 0.87 and $0.97 \mathrm{eV}$, respectively) and this trend is also observed for F/S co-oligomers (FSF, FFSFF, and FSFSF) compared to corresponding homo-oligomers F3 and F5, although the absolute differences are somewhat lower: $\Delta$ (HOMO) $=0.23-0.47 \mathrm{eV}, \Delta($ LUMO $)=0.42-0.54 \mathrm{eV}$ (Ref. 43). Similarly, FASAF shows lower HOMO and LUMO energies compared to FAFAF (by 0.36 and $0.47 \mathrm{eV}$, respectively). The greater effect of the electron-deficient $\mathrm{SO}_{2}$ group on the LUMO energy (compared to its effect on the HOMO) results in contraction of $E_{\mathrm{g}}$ for $\mathrm{F} / \mathrm{S}$ co-oligomers versus the gap in homo-oligomers (by 0.08-0.19 eV). These energy changes upon direct interaction of the electron donor $\mathrm{F}$ and electron acceptor $\mathrm{S}$ reflect charge-transfer interactions (along the $\mathrm{HOMO} \rightarrow$ LUMO excitation) and charge redistribution in the ground electronic state between the units in the backbone (charge polarization), following the same correlation that was deduced by the Raman data. We also compared the B3LYP/6$311(2 d, p)$ orbital energies calculated in this work with literature data on calculations with smaller B3LYP/6-31G(d) basis set. The use of the larger split valence basis set gives lower HOMO (by $0.17-0.23 \mathrm{eV}$ ) and LUMO (by 0.16-0.24 $\mathrm{eV}$ ) energies, while both levels of theory provide an excellent 


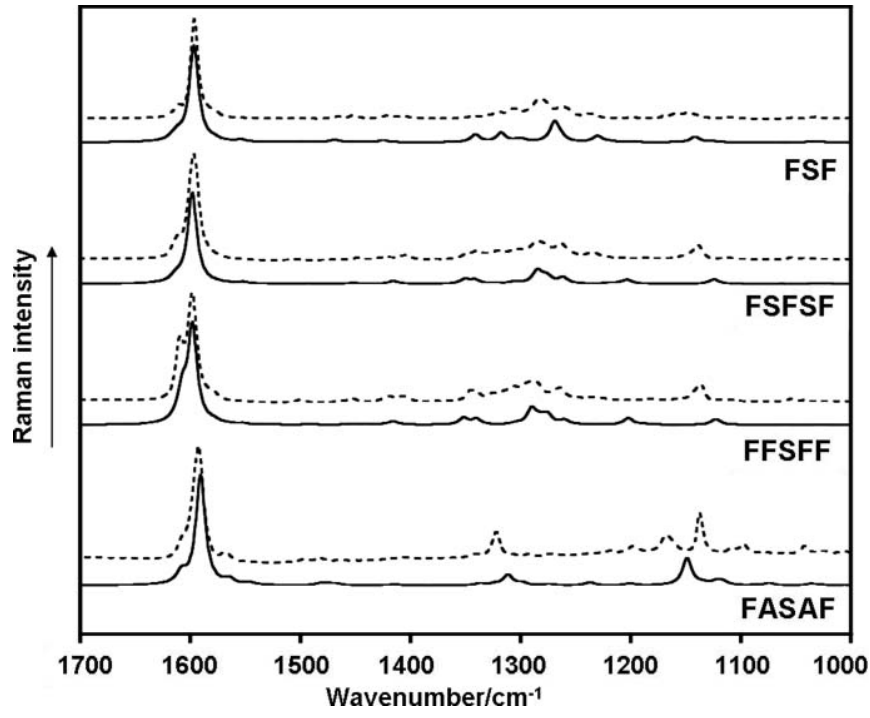

FIG. 9. B3LYP/6-311G(2d,p) Raman spectra of the F/S co-oligomers (solid lines) compared with the experimental ones (dotted lines).

coincidence in the estimation of the HOMO-LUMO energy gaps $\left(\Delta E_{\mathrm{g}}=0-0.04 \mathrm{eV}\right)$.

\section{Theoretical spectra and vibrational dynamics}

The theoretical Raman spectra of the four oligomers in the complete vibrational range are depicted in Fig. 9, which shows a good agreement with the experimental spectra. On the other hand, Fig. 10 shows the calculated eigenvectors for the intense band near $1600 \mathrm{~cm}^{-1}$ for each molecule. In the case of FASAF, where the F and S moieties were separated by $-\mathrm{C} \equiv \mathrm{C}$ - bridges, a wavenumber downshift of $3 \mathrm{~cm}^{-1}$ relatively FSF was observed experimentally (from 1596 to $1593 \mathrm{~cm}^{-1}$ ), which was also successfully predicted by DFT calculations (from 1597 to $1591 \mathrm{~cm}^{-1}$, i.e., $6 \mathrm{~cm}^{-1}$ shift) (Table I). This result also probes an increased contribution of the quinoid structure in FASAF responsible of the frequency downshift. It is also in accordance with the rather low wavenumber measured for the $\mathrm{C} \equiv \mathrm{C}$ stretching vibration

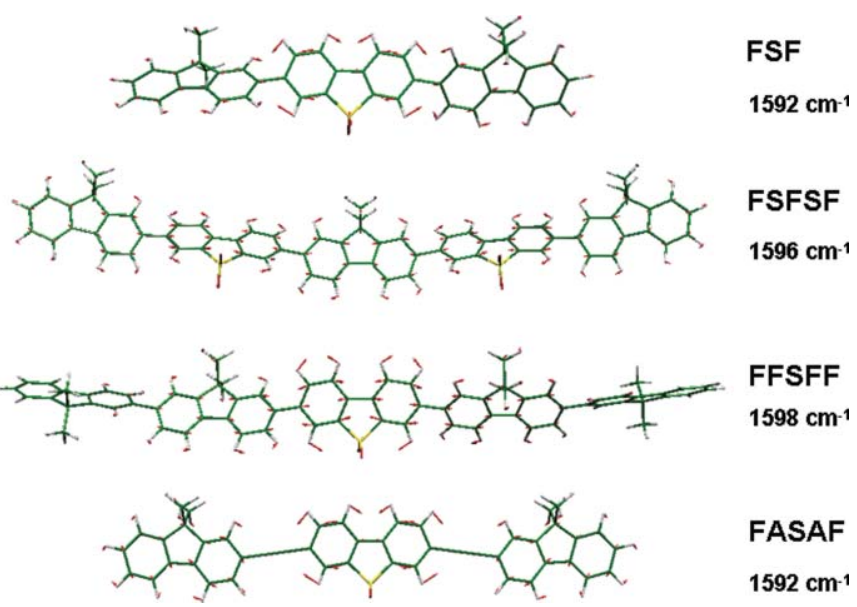

FIG. 10. Calculated eigenvectors for the most intense calculated Raman wavenumbers of F/S co-oligomers.

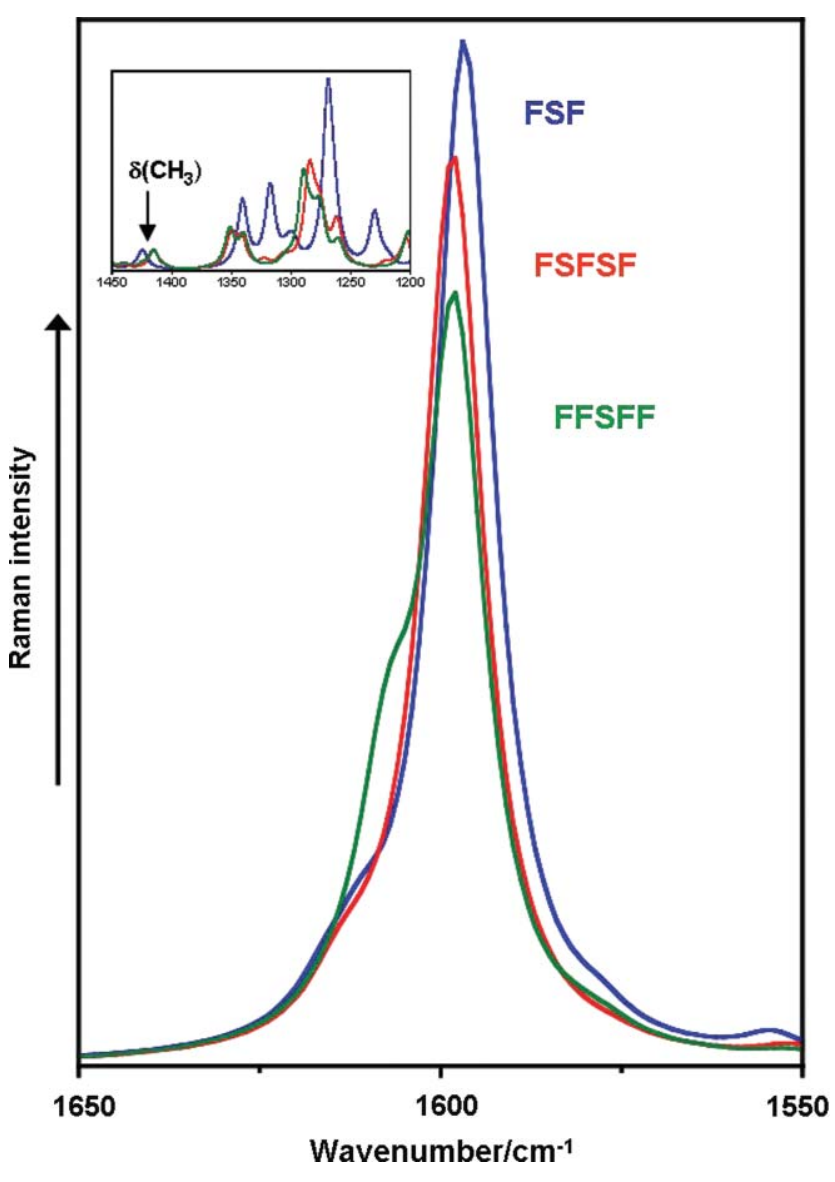

FIG. 11. Comparison between B3LYP/6-311G(2d,p) calculated Raman spectra in the ECC region of FSF, FSFSF and FFSFF normalized to the methyl bending band near $1420 \mathrm{~cm}^{-1}$.

in comparison with nonconjugated triple bonds and with the shortening of the $\mathrm{C}-\mathrm{C}$ inter-ring bonds discussed in the previous section. Thus, the Raman spectra evidence the role of the $\mathrm{C} \equiv \mathrm{C}$ triple bonds in extending the conjugation over the whole molecule, that is, acting as an effective transmitter of $\pi$-electrons between the units at both sides.

Figure 11 compares the theoretical Raman spectra of FSF, FFSFF, and FSFSF (again normalized to the methyl bending band near $1420 \mathrm{~cm}^{-1}$ ). The intensities of the main Я-like band exhibited identical trend as in the experimental spectra [Fig. 7(a)]. We have already assigned the band at $1306 \mathrm{~cm}^{-1}$ (calculated at $1318 \mathrm{~cm}^{-1}$ ) to an aromatic $\mathrm{C}-\mathrm{C}$ stretching vibration in FSF. Thus, one could expect an up-shift of this vibration with an increase of the conjugation length in the co-oligomers: passing from FSF to the five unit members, either by adding to FSF two F endcaps (FFSFF) of by attaching a FS- group to one side (FSFSF), it is observed an appreciable wavenumber up-shift of this Raman band (to 1339 and $1344 \mathrm{~cm}^{-1}$, respectively). This result is indicative of the modulation of $\pi$ conjugation that, contrary to the double $\mathrm{C}=\mathrm{C}$ bonds, reinforces the $\mathrm{C}-\mathrm{C}$ bonds of the central moieties.

\section{E. FSF versus FDBTF: Theoretical Raman spectra and charge polarization}

The B3LYP/6-311G(2d,p) calculated geometry of FDBTF co-oligomer is, in general, consistent with that 

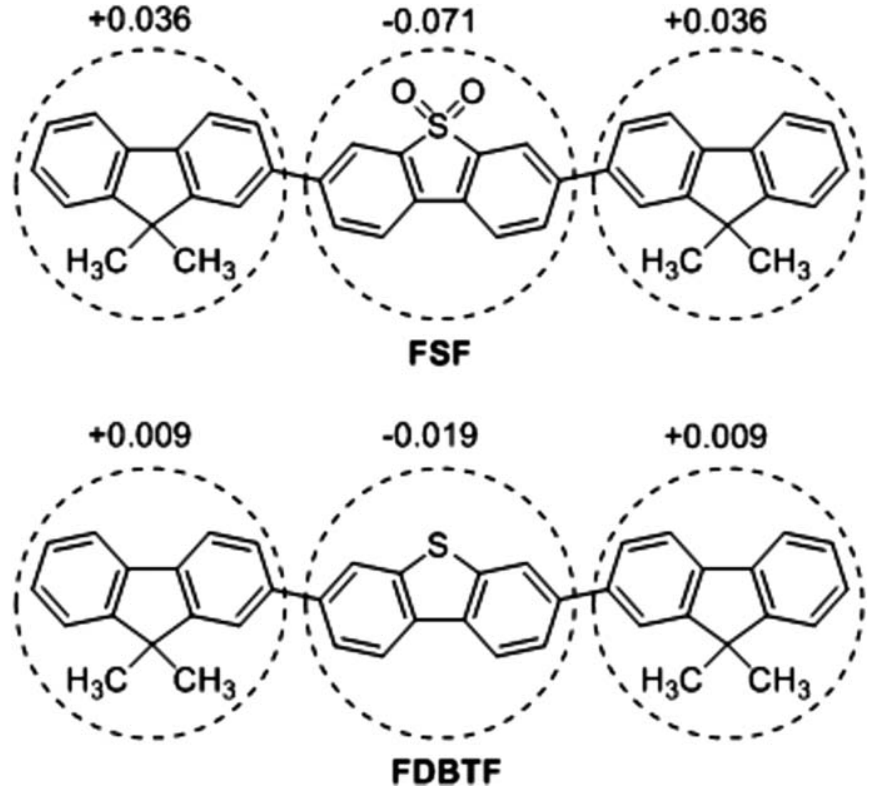

FIG. 12. Charge distribution in FSF and FDBTF, according to DFT B3LYP/6-311G(2d,p) calculations in gas phase.

for FSF, except for the $\mathrm{C}-\mathrm{C}$ bond length between the benzene rings in the DBT unit, which is shorter $(1.448 \AA$ versus $1.472 \AA$ in FSF, Figs. 2 and 3).

Recently we demonstrated by UV-Vis absorption and fluorescence studies that an excited state intramolecular charge transfer, existing in fluorine-dibenzothiophene- $S$, $S$-dioxide oligomers (FSF, FASAF, FFSFF, and FSFSF), as well as in $(\mathrm{F} / \mathrm{S})_{n}$ co-polymers, ${ }^{19,21,22}$ completely disappeared when the electron-deficient $S$ moiety was replaced by the dibenzothiophene moiety. Both the FDBTF oligomer and $(\mathrm{F} / \mathrm{DBT})_{n}$ copolymers did not show ICT in their excited states, however. $^{21}$ This can be understood as the sulfur atom in DBT, in contrast to the $\mathrm{SO}_{2}$ group in the $\mathrm{S}$ moiety, is only weakly electron withdrawing and more comparable with the carbon atom (C-9) in fluorene.

In order to study the effect of the different oxidation state of sulfur in dibenzothiophene ( $\mathrm{S}$ versus $\mathrm{SO}_{2}$ ) on the ground state charge polarization (charge distribution in FBDTF and FSF oligomers) and how this affects the Raman spectra, we performed new structural optimization and force field calculations. DFT revealed that in the optimized geometries, the LUMO energy in DBT is only slightly lower than in fluorene $(\mathrm{F})$ (by $0.19 \mathrm{eV}$ ), whereas $\mathrm{S}$ showed much lower LUMO energy shift (by $0.97 \mathrm{eV}$ ) (see Table SM2 of Ref. 43). The same trend was also observed for the trimers: LUMO energy levels for FFF, FDBTF, and FSF oligomers were $-1.61,-1.71$, and $-2.17 \mathrm{eV}$, respectively. Similarly, the HOMO energies for FFF and FDBTF are quite close ( -5.41 and $-5.55 \mathrm{eV}$, respectively) while the HOMO energy for FSF is considerably lower $(-5.80 \mathrm{eV})$. These resulted in lower $E_{\mathrm{g}}$ for FSF compared to FDBTF and FFF (3.65, 3.84, and $3.80 \mathrm{eV}$, respectively) (Table SI2). Moreover, the analysis of the charge distribution in FDBTF versus FSF revealed the differences between Mulliken charges on the different moieties. Rather small positive charges on F and small negative charge on DBT were found

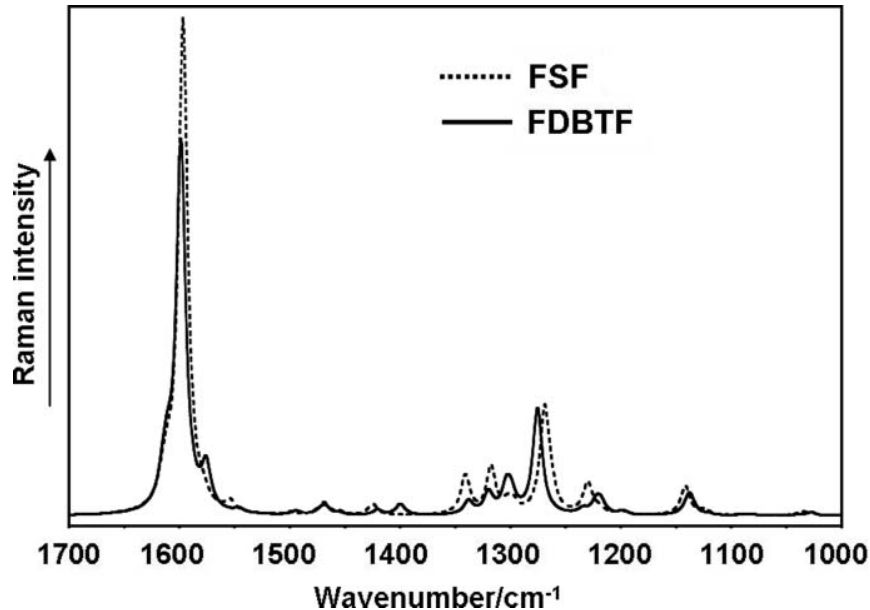

FIG. 13. B3LYP/6-311G(2d,p) calculated Raman spectra of FSF and FDBTF.

in FDBTF $(+0.009 e /-0.019 e /+0.009 e)$, while FSF showed more pronounced alternation in net charges on the moieties $(+0.036 e /-0.071 e /+0.036 e)$ (Fig. 12). This suggests that, compared to FSF, where the charge polarization property is relevant, in FDBTF this is negligible and the relevant interaction is $\pi$ conjugative.

The theoretical Raman spectra for FSF and FDBTF are shown in Fig. 13. In general, the spectral pattern of FDBTF, compared to FSF, does not significantly change, which means again that FDBTF preserves a relevant electronic conjugation over the long molecular axis. As a consequence of this effect, from FSF to FDBTF, up-shifts of the bands at $1597(+2)$, $1547(+8)$ and $1269(+7) \mathrm{cm}^{-1}$ and downshifts of those at $1230(-9)$ and $1142(-4) \mathrm{cm}^{-1}$ were observed. From a structural point of view, these data indicate the less quinoidal pattern in FDBTF due to the removing of the charge polarization term promoted by the donor-to-acceptor interaction such as seen in the charge distribution above.

\section{F. Comparative studies of solid/solution/melted states: Raman monitoring in FFSFF}

To follow the effect of intermolecular interactions on the spectral characteristics in the samples, we have studied the spectra of FFSFF in dichloromethane solution and in the solid state at room temperature, and in the melted phase over $225^{\circ} \mathrm{C}$ (Fig. 14). The region around $1600 \mathrm{~cm}^{-1}$ $\left[v_{\mathrm{C}=\mathrm{C}}(\mathrm{S})\right.$ (ECC mode) and $v_{\mathrm{C}=\mathrm{C}}$ (b) Raman bands] was selected for the analysis. Spectral broadening and a lack of spectral resolution was observed in the melted and solution phases due to the distribution of molecular conformers arising from thermal heating (for the melted sample) and from solute-to-solvent interactions, respectively (see the discussion of the dihedral angles between the units). In contrast, the solid state sample demonstrated two clearly resolved and narrow bands. The maxima of these two peaks measured for solid state/solution/melted phase were found at 1598/1600/1595 $\mathrm{cm}^{-1}$ and $1610 / 1610 \mathrm{sh} / 1603 \mathrm{sh} \mathrm{cm}^{-1}$, respectively.

In the freely adopted distorted conformation of FFSFF in solution, which resulted with $\sim 37.3-38.1^{\circ}$ dihedral angles 


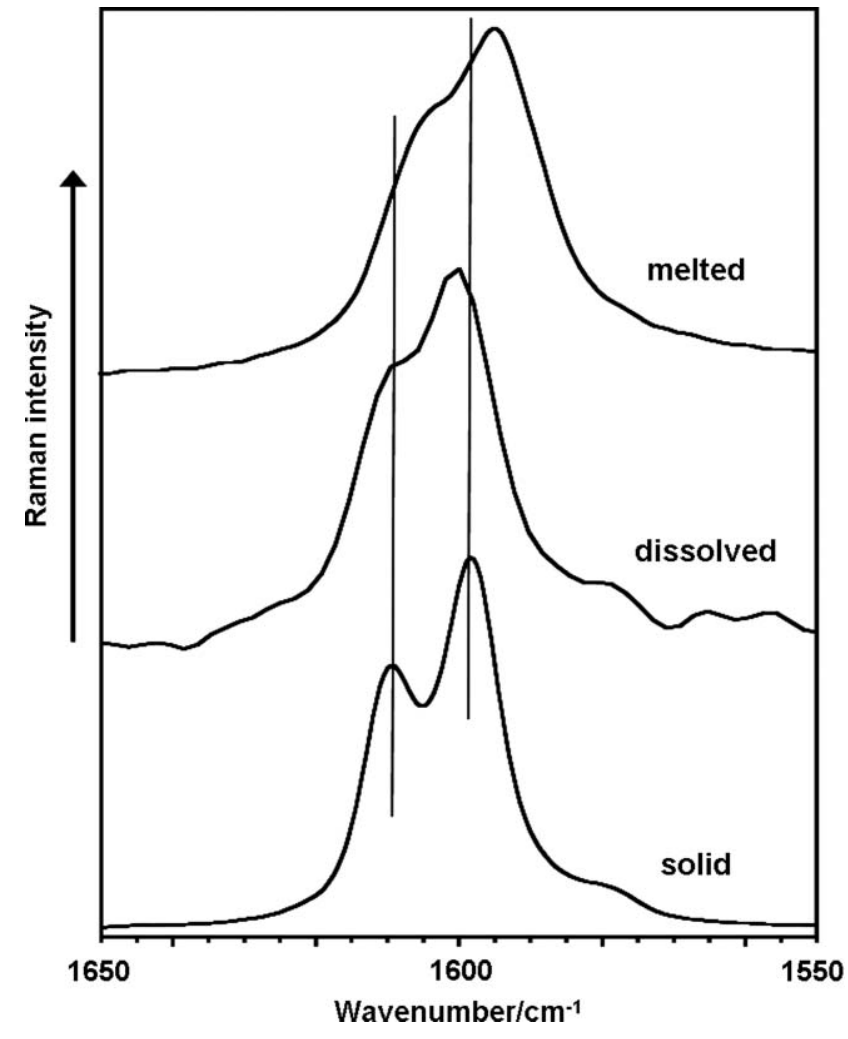

FIG. 14. Comparison of the Raman spectra of FFSFF in the solid state and in DCM solution (at $25^{\circ} \mathrm{C}$ ) and in melted phase (at $225^{\circ} \mathrm{C}$ ).

between the F and S moieties, according to DFT due to the steric hindrance between the moieties, the most intense band appeared at $1600 \mathrm{~cm}^{-1}$ (i.e., $1598 \mathrm{~cm}^{-1}$ in the solid state at room temperature). This $2 \mathrm{~cm}^{-1}$ up-shift might be a consequence of the electronic disconnection between the successive distorted units in solution. Somewhat surprisingly these Raman bands in the melted phase are down-shifted relative to the solid. Logically, one would expect these frequencies to be half-way between the solid and the solution cases. This finding is unclear for us and reveals the importance of intermolecular interactions on the position of these Raman vibrations as well.

\section{CONCLUSIONS}

In this paper we have used Raman spectroscopy and DFT quantum chemical calculations to elucidate structureproperty relationships which originate from charge polarization due to the donor-to-acceptor interaction (the same origin than the photoinduced intramolecular charge transfer) and $\pi$ conjugation along the main molecular axis. The study has focused on a series of fluorene (F) co-oligomers with dibenzothiophene- $S, S$-dioxide (S) moieties (FSF, FSFSF, and FFSFF), a co-oligomer containing acetylene (A) bridges (FASAF) and a co-oligomer with dibenzothiophene (DBT) moiety (FDBTF). Thus, the presence of alternating electron donating $\mathrm{F}$ and accepting $\mathrm{S}$ moieties, together with $\mathrm{A}$ as a bridge for electron transmission, has allowed us to investigate the effect of varying their number and relative position on the $\pi$ conjugation and charge polarization.
Within the framework of ECC theory, we analyzed the $\pi$-conjugational properties and the effect of the charge polarization along the co-oligomers backbones in the ground electronic state arising from the alternation of the electron donor and electron acceptor units. These studies suppose that the strongest Raman features have a common collective vibrational mode, which describes an aromatic-to-quinoid structural transition and consequently contains the relevant information about the evolution of the electronic property. The efficiency of $\pi$ conjugation has been described by the particular enhancement of skeletal coupled $\mathrm{C}=\mathrm{C}$ stretching modes, which displayed wavenumber downshift with: (i) increasing of $\pi$ conjugation associated with the enlargement of the co-oligomer size (i.e., number of $\mathrm{F}$ and $\mathrm{S}$ units in the backbone) and (ii) with the slight quinoidization of the benzenoid structures due to donor-acceptor interaction (particularly facilitated by the acetylene $\pi$ bridges which planarize the system). Comparative studies of co-oligomers with $\mathrm{S}$ and DBT moieties reveal the importance of charge polarization induced by the strongly electron-withdrawing $\mathrm{SO}_{2}$ group, and its effect on the Raman spectra. Finally, a comparison of solution, solid state and melted phase Raman spectra for FFSFF demonstrated the importance of intermolecular interactions on the Raman vibrational properties.

In summary, we have demonstrated that the intensity and frequency of the Raman bands in conjugated fluorene-based co-oligomers are sensitive to both intra- and intermolecular effects. A combination of theoretical DFT and experimental Raman spectra has provided a deep insight into the molecular and electronic structures of these materials which are attracting considerable attention as active layers in organic electronics devices.

\section{ACKNOWLEDGMENTS}

The Spanish Ministry of Science and Technology, Grant CTQ2009-10098/BQU has supported this work.

${ }^{1}$ J. H. Burroughes, D. D. C. Bradley, A. R. Brown, R. N. Marks, K. Makcay, R. H. Friend, P. L. Brun, and A. B. Holmes, Nature (London) 347, 539 (1990).

${ }^{2}$ D. F. Perepichka, I. F. Perepichka, H. Meng, and F. Wudl, Organic LightEmitting Materials and Devices, edited by Z. Li and H. Meng (CRC, Boca Raton, 2007), Chap. 2, pp. 45.

${ }^{3}$ A. C. Grimsdale, K. L. Chan, R. E. Martin, P. G. Jokisz, and A. B. Holmes, Chem. Rev. 109, 897 (2009), and references cited therein.

${ }^{4}$ D. F. Perepichka, H. Meng, and F. Wudl, Adv. Mater. 17, 2281 (2005); M. Muccini, Nature Mater. 5, 605 (2006).

${ }^{5}$ K. T. Kamtekar, A. P. Monkman, and M. R. Bryce, Adv. Mater. 22, 572 (2010).

${ }^{6}$ Handbook of Conducting Polymers. Conjugated Polymers. Vol.1: Theory, Synthesis, Properties, and Characterization. Vol. 2: Processing and Applications, edited by T. A. Skotheim and J. R. Reynolds (CRC, Boca Raton, 2007).

${ }^{7}$ Electronic Materials: The Oligomer Approach, edited by K. Müllen, G. Wegner (Wiley-VCH, Weinheim, 1998), p 599.

${ }^{8}$ A. Mishra, C.-Q. Ma, P. Bäuerle, Chem. Rev. 109, 1141 (2009).

${ }^{9}$ A. L. Kanibolotsky, I. F. Perepichka, P. J. Skabara, Chem. Soc. Rev. 39, 2695 (2010).

${ }^{10}$ H. Haick and D. Cahen, Acc. Chem. Res. 41, 359 (2008); R. L. McCreery, Chem. Mater. 16, 4477 (2004); H. Haick and D. Cahen, Prog. Surf. Sci. 83, 217 (2008).

${ }^{11}$ C. Wang, A. S. Batsanov, M. R. Bryce, S. Martín, R. J. Nichols, S. J. Higgins, V. M. García-Suárez, and C. J. Lambert, J. Am. Chem. Soc. 131, 
15647 (2009); B. Q. Xu, X. L. Li, X. Y. Xiao, H. Sakaguchi, and N. J. Tao, Nano Lett. 5, 1491 (2005)

${ }^{12}$ Advances in Polymer Science Vol. 212, Polyfluorenes, edited by U. Scherf, D. Neher (Springer-Verlag, Berlin, 2008), p. 322.

${ }^{13}$ M. Knaapila, R. Stepanyan, B. P. Lyons, M. Torkkeli, and A. P. Monkman, Adv. Funct. Mater. 16, 599 (2006).

${ }^{14}$ J. Roncali, Chem. Rev. 97, 173 (1997).

${ }^{15}$ S.-J. Chung, M. Rumi, V. Alain, S. Barlow, J. W. Perry, and S. R. Marder. J. Am. Chem. Soc. 127, 10844 (2005); L. Porrès, O. Mongin, C. Katan, M. Charlot, T. Pons, J. Mertz, and M. Blanchard-Desce, Org. Lett. 6, 47 (2004); Z. Suo, M. Drobizhev, C. W. Spangler, N. Christensson, and A. Rebane, Org. Lett. 7, 4807 (2005); O. Mongin, L. Porrès, M. Charlot, C. Katan, and M. Blanchard-Desce, Chem. -Eur. J. 13, 1481 (2007); G.J. Zhou, W.-Y. Wong, Z. Lin, and C. Ye, Angew. Chem., Int. Ed. 45, 6189 (2006); G.-J. Zhou, W.-Y. Wong, D. Cui, and C. Ye, Chem. Mater. 17, 5209 (2005); D. W. Brousmiche, J. M. Serin, J. M. J. Fréchet, G. S. He, T.-C. Lin, S. J. Chung, and P. N. Prasad, J. Am. Chem. Soc. 125, 1448 (2003).

${ }^{16}$ D. F. Perepichka and M. R. Bryce, Angew. Chem. Int. Ed. 44, 5370 (2005).

${ }^{17}$ R. M. Metzger, Chem. Rev. 103, 3803 (2003).

${ }^{18}$ I. I. Perepichka, I. F. Perepichka, M. R. Bryce, L.-O. Pålsson, Chem. Commun. 2005, 3397.

${ }^{19}$ F. B. Dias, S. Pollock, G. Hedley, L.-O. Pålsson, A. Monkman, I. I. Perepichka, I. F. Perepichka, M. Tavasli, and M. R. Bryce, J. Phys. Chem. B 110, 19329 (2006).

${ }^{20}$ G. Barbarella and M. Melucci, in Handbook of Thiophene-Based Materials. Applications in Organic Electronics and Photonics, edited by I. F. Perepichka and D. F. Perepichka (Wiley, Chichester, UK, 2009), Vol. 1, Chap. 4, pp. 255-292.

${ }^{21}$ F. B. Dias, S. King, A. P. Monkman, I. I. Perepichka, M. A. Kryuchkov, I. F. Perepichka, and M. R. Bryce, J. Phys. Chem. B 112, 6557 (2008).

${ }^{22}$ S. M. King, I. I. Perepichka, I. F. Perepichka, F. B. Dias, M. R. Bryce, and A. P. Monkman, Adv. Funct. Mater. 19, 586 (2009).

${ }^{23}$ Y. Li, H. Wu, J. Zou, L. Ying, W. Yang, and Y. Cao, Org. Electron. 10, 901 (2009); J. Liu, J. H. Zou, H. B. Wu, W. Yang, C. Li, B. Zhang, Y. Y. Li, J. B. Peng, and Y. Cao, Chem. Mater. 20, 4499 (2008); J. Liu, S. Hu, W. Zhao, Q. Zou, W. Luo, W. Yang, J. Peng, and Y. Cao, Macromol. Rapid Commun. 31, 496 (2010); K. T. Kamtekar, H. L. Vaughan, B. P. Lyons, A. P. Monkman, S. U. Pandya, and M. R. Bryce, Macromolecules 43, 4481 (2010)..

${ }^{24}$ M. Tavasli, S. Bettington, I. F. Perepichka, A. S. Batsanov, M. R. Bryce, C. Rothe, and A. P. Monkman, Eur. J. Inorg. Chem. 2007, 4808; W.-S Huang, Y.-H. Wu, Y.-C. Hsu, H.-C. Lin, J. T. Lin, Polymer 50, 5945 (2009).

${ }^{25}$ G. Grisorio, G. Melcarne, G. P. Suranna, P. Mastrorilli, C. F. Nobile, P. Cosma, P. Fini, S. Colella, E. Fabiano, M. Piacenza, F. Della Sala, G. Ciccarella, M. Mazzeo, and G. Gigli, J. Mater. Chem. 20, 1012 (2010).

${ }^{26}$ M. Gussoni, C. Castiglioni, and G. Zerbi, in Spectroscopy of Advanced Materials, edited by R. J. Clark, R. W. Hester (Wiley, New York, 1991), pp. 251.

${ }^{27}$ A. Sakamoto, Y. Furukawa, and M. Tasumi, J. Phys. Chem. 98, 4635 (1994); N. Yokonuma, Y. Furukawa, M. Tasumi, M. Kuroda, and J. Nakayama, Chem. Phys. Lett. 255, 431 (1996).

${ }^{28}$ I. Harada and Y. Furukawa, in Vibrational Spectra and Structure, edited by J. Durig (Elsevier, Amsterdam, 1991), Chap. 19, pp. 369.

${ }^{29}$ V. Hernandez, J. Casado, F. J. Ramirez, G. Zotti, S. Hotta, and J. T. Lopez Navarrete, J. Chem. Phys. 104, 9271 (1996); J. Casado, V. Hernandez, S. Hotta, and J. T. Lopez Navarrete, J. Chem. Phys. 109, 10419 (1998); C. Moreno Castro, M. C. Ruiz Delgado, V. Hernandez, S. Hotta, J. Casado, and J. T. Lopez Navarrete, J. Chem. Phys. 116, 10419 (2002); C. Moreno Castro, M. C. Ruiz Delgado, V. Hernandez, Y. Shirota, J. Casado, and J. T. Lopez Navarrete, J. Phys. Chem. B 106, 7163 (2002).

${ }^{30} \mathrm{~V}$. Hernandez, J. Casado, F. Effenberger, and J. T. Lopez Navarrete, J. Chem. Phys. 112, 5105 (2000); S. M. C. Ruiz Delgado, V. Hernandez, J. Casado, J. T. Lopez Navarrete, J. M. Raimundo, P. Blanchard, and J. Roncali, Chem. -Eur. J. 9, 3670 (2003); D. Ledesma, R. Ponce Ortiz, M. C. Ruiz Delgado, Y. Vida, E. Perez-Inestrosa, J. Casado, V. Hernandez, O. K. Kim, J. M. Lehn, and J. T. Lopez Navarrete, Chem. -Eur. J. 10, 3805 (2004).
${ }^{31}$ M. Gonzalez, J. L. Segura, C. Seoane, N. Martin, J. Garin, J. Orduna, R. Alcala, B. Villacampa, V. Hernandez, and J. T. Lopez Navarrete, J. Org. Chem. 66, 8872 (2001); J. Casado, T. M. Pappenfus, L. L. Miller, K. R. Mann, E. Orti, P. Viruela, R. Pou-Amerigo, V. Hernandez, and J. T. Lopez Navarrete, J. Am. Chem. Soc. 125, 2534 (2003).

${ }^{32}$ G. Zerbi, C. Castiglioni, and M. Del Zoppo, in Electronic Materials: The Oligomer Approach, edited by K. Müllen and G. Wegner (Wiley-VCH, Weinheim, Germany, 1998), Chap. 6, p 345; C. Castiglioni, M. Gussoni, J. T. López Navarrete, and G. Zerbi, Solid State Commun. 65, 625 (1988); J. T. López Navarrete and G. Zerbi, J. Chem. Phys. 94, 957 (1991); V. Hernández, C. Castiglioni, M. Del Zoppo, and G. Zerbi, Phys. Rev. B, 50, 9815 (1994); E. Agosti, M. Rivola, V. Hernández, M. Del Zoppo, and G. Zerbi, Synth. Metals 100, 101 (1999); M. Del Zoppo, C. Castiglioni, P. Zuliani, and G. Zerbi, in Handbook of Conducting Polymers, edited by T. A. Skotheim, R. L. Elesenbaumer, and J. R. Reynolds, 2nd ed. (Marcel Dekker, New York, 1998), Chap. 28, p. 765.

${ }^{33}$ M. J. Frisch, G. W. Trucks, H. B. Schlegel, G. E. Scuseria, M. A. Robb, J. R. Cheeseman, J. J. A. Montgomery, T. Vreven, K. N. Kudin, J. C. Burant, J. M. Millam, S. S. Iyengar, J. Tomasi, V. Barone, B. Mennucci, M. Cossi, G. Scalmani, N. Rega, G. A. Petersson, H. Nakatsuji, M. Hada, M. Ehara, K. Toyota, R. Fukuda, J. Hasegawa, M. Ishida, T. Nakajima, Y. Honda, O. Kitao, H. Nakai, M. Klene, X. Li, J. E. Knox, H. P. Hratchian, J. B. Cross, V. Bakken, C. Adamo, J. Jaramillo, R. Gomperts, R. E. Stratmann, O. Yazyev, A. J. Austin, R.Cammi, C. Pomelli, J. W. Ochterski, P. Y. Ayala, K. Morokuma, G. A. Voth, P. Salvador, J. J. Dannenberg, V. G. Zakrzewski, S. Dapprich, A. D. Daniels, M. C. Strain, O. Farkas, D. K. Malick, A. D. Rabuck, K. Raghavachari, J. B. Foresman, J. V. Ortiz, Q. Cui, A. G. Baboul, S. Clifford, J. Cioslowski, B. B. Stefanov, G. Liu, A. Liashenko, P. Piskorz, I. Komaromi, R. L. Martin, D. J. Fox, T. Keith, M. A, Al-Laham, C. Y. Peng, A. Nanayakkara, M. Challacombe, P. M. W. Gill, B. Johnson, W. Chen, M. W. Wong, C. Gonzalez, J. A. Pople, Gaussian03, Revisions D.02 and E.01, Gaussian, Inc., Wallingford, CT, 2004.

${ }^{34}$ A. D. Becke, J. Chem. Phys. 98, 5648 (1993).

${ }^{35}$ P. J. Stephens, F. J. Devlin, C. F. Chabalowski, and M. J. Frisch, J. Phys. Chem. 98, 11623 (1994).

${ }^{36}$ K. Kim and K. D. Jordan, J. Phys. Chem. 98, 10089 (1994).

${ }^{37}$ P. C. Hariharan and J. A. Pople, Theor. Chim. Acta 28, 213 (1973).

${ }^{38}$ T. Clark, J. Chandrasekhar, G. W. Spitznagel, and P. V. R. Schleyer, J. Comput. Chem. 4, 294 (1983).

${ }^{39}$ E. K. U. Gross and W. Kohn, Adv. Quantum Chem. 21, 255 (1990).

${ }^{40}$ A. P. Scott and L. Radom, J. Phys. Chem. 100, 16502 (1996).

${ }^{41}$ G. Hughes, C. Wang, A. S. Batsanov, M. Fern, S. Frank, M. R. Bryce, I. F. Perepichka, A. P. Monkman, and B. P. Lyons, Org. Biomol. Chem. 1, 3069 (2003).

${ }^{42}$ S. Oyston, C. Wang, G. Hughes, A. S. Batsanov, I. F. Perepichka, M. R. Bryce, J. H. Ahn, C. Pearson, and M. C. Petty, J. Mater. Chem. 15, 194 (2005).

${ }^{43}$ See supplementary material at http://dx.doi.org/10.1063/1.3526487 for a list of calculated and experimental wavenumbers, Raman activities, and assignments.

${ }^{44}$ E. B. Wilson, Jr., J. C. Decius, and P. C. Cross, Molecular Vibrations (McGraw-Hill, New York, 1955).

${ }^{45}$ G. Heimel, D. Somitsch, P. Knoll, and E. Zojer, J. Chem. Phys. 116, 10921 (2002); G. Heimel, D. Somitsch, P. Knoll, J.-L. Brédas, and E. Zojer, J. Chem. Phys. 122, 114511 (2005); S. Guha, W. Grapner, R. Resel, M. Chandrasekhar, R. H. Chandrasekhar, R. Glaser, and G. Leising, Phys. Rev. Lett. 82, 3625 (1999); S. Guha, J. D. Rice, C. M. Martin, W. Grapner, M. Chandrasekhar, R. H. Chandrasekhar, and U. Scherf, Synthetic Metals 708, BB10.7.1 (2002).

${ }^{46}$ L. Cuff, M. Kertesz, U. Scherf, and K. Müllen, Synth. Metals 69, 683 (1995); L. L. Cuff, C. Cui, and M. Kertesz, J. Am. Chem. Soc. 116, 9269 (1994); L. Cuff and M. Kertesz, J. Phys. Chem. 98, 12223 (1994); L. Cuff and M. Kertesz, Macromolecules 27, 762 (1994).

${ }^{47}$ G. Socrates, Infrared and Raman Characteristic Group Frequencies, (Wiley, Chichester, UK, 2009).

${ }^{48}$ D. Mayo, F. A. Miller, and R. W. Hannah, Curse Notes on the Interpretation of Infrared and Raman Spectra (John Wiley \& Sons, Hoboken, 2004).

${ }^{49}$ L. R. Kronfeld and R. L. Sass, Acta Crystallogr. B 24, 981 (1968). 